\title{
CARACTERES MORFOLÓGICOS E ANATÔMICOS ÚTEIS NA SISTEMÁTICA VEGETAL: ESTUDO NOS GÊNEROS VISMIA (HYPERICACEAE) E CLUSIA (CLUSIACEAE)
}

\section{Bianca de Almeida Maia Carvalho, Haziel Sixto Baden Sanchez Hermoza, Sabrina Procópio Bueno de Jesus.}

\section{Resumo}

O presente projeto tem como objetivo investigar dois gêneros de plantas brasileiras com muitas espécies e que possuem poucos estudos sistemáticos recentes: Vismia (Hypericaceae) e Clusia (Clusiaceae). Espécies de outras famílias também foram estudadas, com a finalidade de estudar sua morfologia vegetativa e reprodutiva.

\section{Palavras-chave:}

Vismia, Clusia, Sistemática Vegetal

\section{Introdução}

A sistemática vegetal estuda a diversidade dos organismos: sua descoberta, descrição, classsificação e estudos de sua filogenia. Essa informação é disponibilizada em sistemas de classificação preditivos. Neste projeto, conhecemos as características dos gêneros Vismia (Hypericaceae) e Clusia (Clusiaceae). Uma das características notáveis de Vismia é a pilosidade nos ramos, folhas e nas estruturas florais, especialmente nas pétalas. Por sua vez, as espécies do gênero Clusia possuem morfologia das flores muito variável, e em geral são unissexuadas, com flores masculinas e femininas em plantas distintas. Nosso objetivo foi aprender sobre ambos os gêneros para poder criar uma ferramenta de identificação.

\section{Resultados e Discussão}

No início do projeto, aprendemos sobre morfologia das plantas. Depois fizemos coletas pelo Campus e estudamos as plantas no laboratório. Fizemos cortes de ramos jovens de espécies de Clusia, com muitos canais, que foram visualizados com o auxilio do microscópio. Realizamos também clarificação de pétalas de espécies de Vismia e de Clusia, para observar suas nervuras. Finalmente, elaboramos chaves de identificação, começando pelas dicotômicas (impressas) e depois as interativas de entradas múltiplas, utilizadas com auxílio de computadores.

(A)

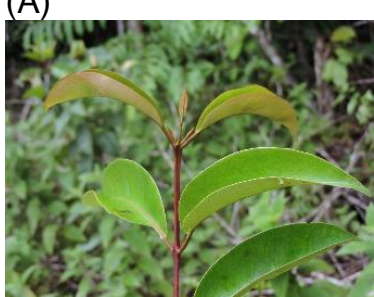

(B)

(C)

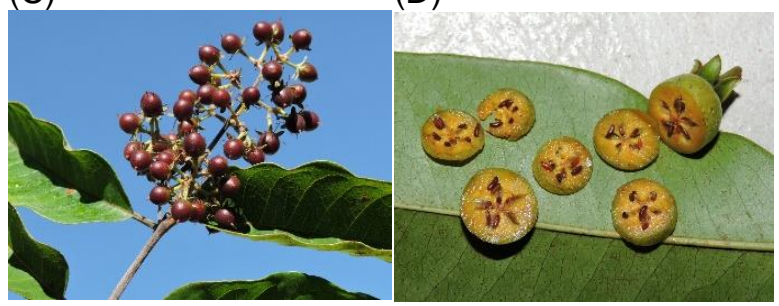

(A)

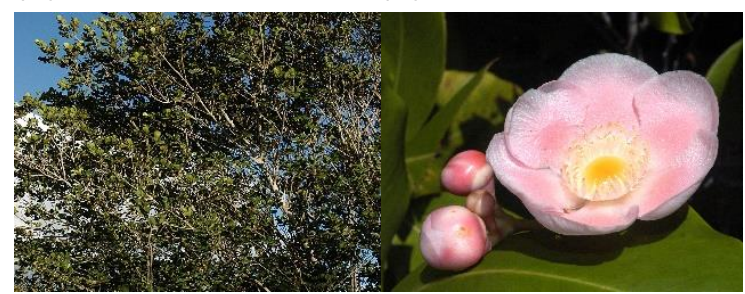

(C)

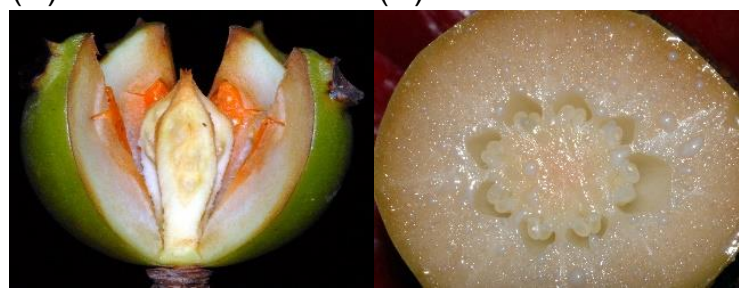

Figura 2. A: hábito de Clusia cf. paralicola G. Mariz; B: flor de C. palmicida Rich. ex Planch. \& Triana; C: fruto aberto de C. aff. weddelliana Planch. \& Triana; D: fruto cortado de $C$. aff. lanceolata Cambess.

\section{Conclusões}

Durante o desenvolvimento do projeto, aprendemos muitos aspectos importantes no estudo da botânica: sobre métodos de coleta e documentação fotográfica de plantas, e como interpretar sua morfologia e anatomia. Aprendemos também a identificar plantas utilizando diversos tipos de chaves de identificação. Finalmente, aprendermos a elaborar chaves de identificação ilustradas, tanto dicotômicas, elaboradas manualmente, quanto interativas de entradas múltiplas, elaboradas e utilizadas com auxílio de programas como o Lucid.

\section{Agradecimentos}

Agradecemos à Pró-Reitoria de Pesquisa da UNICAMP pela oportunidade de participar do projeto, ao CNPq pelas bolsas PIBIC-EM, à FAPESP e ao FAEPEX/UNICAMP pelo apoio, à orientadora Maria do Carmo $\mathrm{E}$.

Amaral e, pela participação e ajuda, aos pesquisadores Ana Cláudia Alencar, Milena V. Martins, Gustavo H. Shimizu e Volker Bittrich.

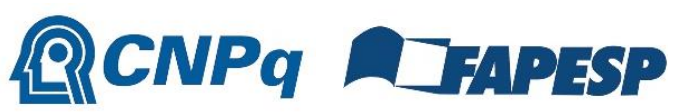

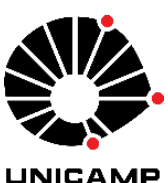

Figura 1. A: folhas de Vismia cayennensis (Jacq.) Pers.; B: flor de $V$. japurensis Reichardt; C: frutos de $V$. brasiliensis Choisy; D: frutos cortados de $V$. cayennensis. 